\title{
Efficacy of combination of tablet mifepristone and misoprostol for first trimester pregnancy termination at different gestational age
}

\section{Poonam Bhojwani, Pragati Meena*, Gajendra Singh Verma}

Department of Obstetrics and Gynecology, NIMS Medical College, Jaipur, Rajasthan, India

Received: 09 November 2017

Accepted: 02 December 2017

\section{*Correspondence:}

Dr. Pragati Meena,

E-mail:drpragati02@gmail.com

Copyright: (C) the author(s), publisher and licensee Medip Academy. This is an open-access article distributed under the terms of the Creative Commons Attribution Non-Commercial License, which permits unrestricted non-commercial use, distribution, and reproduction in any medium, provided the original work is properly cited.

\begin{abstract}
Background: Medical method of abortion is a safe, effective and affordable method for first trimester termination. However, nausea, vomiting, diarhoea, excess bleeding and incomplete abortion are known side effects. The aim of study was to compare the success rate of abortions in both groups, to compare the induction-abortion interval in both groups and to study the side effects of the drugs.

Methods: This study was conducted in department of obstetrics and gynecology, NIMS Medical College, Jaipur, India during June 2017-August 2017. Total hundred cases were taken and divided into two groups. Group A was gestational age upto 49 days, Group B was gestational age 50-63 days. Both groups were given tab. mifepristone 200mg. followed by $48 \mathrm{hrs}$. by 4 tablets of tab misoprostol.

Results: The results of the given regimen were highly successful and complete abortion was achieved in $96 \%$ and 94\% in group A and group B respectively. The difference between two groups was statistically not significant (p value $=0.64$ ). Failure rates were seen in only $4 \%$ of group A and $6 \%$ of group B. Pain abdomen was seen in $16 \%$ of group A and $38 \%$ of group B patients. The difference between both groups was statistically significant (p value $=0.02$ ). Nausea was seen in $10 \%$ of group A and $30 \%$ of group B patients. The difference between both groups is statistically significant $(\mathrm{p}$ value $=0.018$ ).

Conclusions: First trimester pregnancy can be successfully terminated with combination of mifepristone and misoprostol upto 63 days (9 weeks) of pregnancy.
\end{abstract}

Keywords: Mifepristone, Misoprostol, Termination of pregnancy

\section{INTRODUCTION}

Abortion is willful termination of pregnancy before period of viability. In most cases it is an unwanted pregnancy. ${ }^{1}$ Each year throughout world approx. 210 million women become pregnant and around 130 million of them deliver live born infants.

Approx. 46 million pregnancy are voluntarily terminated each year and around 19 million unsafe abortions are performed.,3 In India almost 15000-20000 women die each year because of complication of unsafe abortion. ${ }^{4}$
Unsafe abortions are a cause of maternal morbidity, so Gov. of India passed MTP act in 1971 which came in force from April 2, 1972.

WHO recommendations on medical abortion are restricted to early first trimester (upto 63 days since the first day of last menstrual period).$^{5}$

Tab mifepristone (RU486) is antiprogestrone drug and misoprostol is a synthetic prostaglandin analog which was marketed for first time in 1985 for the prevention of NSAIDS induced gasrtric ulcer. ${ }^{6}$ 
Both drugs are USFDA approved for medical abortion.

DCGI (drug controller general of India) has approved a combipack of one $200 \mathrm{mg}$. tablet of mifepristone and four $200 \mathrm{mcg}$. of misoprostol for medical method of abortion up to 63 days. $^{3}$

Vacuum aspiration (mechanical or electrical) was the most popular method of doing first trimester abortions till recently when abortifacient agents such as antiprogesterone (Mifepristone) and prostaglandins (Misoprostol) were approved by United States Food and Drug Administration in 2000 for first trimester pregnancy termination

Mifepristone acts in several ways but its main action is to block the action of progesterone, a hormone necessary to sustain pregnancy and misoprostol causes uterine contractions, which expels the foetus and other products of conception. ${ }^{7}$

There are certain advantages and disadvantages of surgical and medical methods of inducing abortion. The main advantages of medical abortions are that surgical and anaesthetic risks are avoided and the procedure is less painful than surgical abortion under local anaesthesia. The disadvantages of medical abortion are that it requires longer period for completion, multiple visits and it is not available after certain period of amenorrhea. $^{8}$

Initially when mifepristone was approved for first trimester abortions, a higher dose of $600 \mathrm{mg}$ was recommended. However, similar results have been achieved with a much lower dose of $200 \mathrm{mg} .{ }^{9,10}$ In this study we have used a lower dose of $200 \mathrm{mg}$ mifepristone.

Initially there were concerns about the use of this method in India as the cost of mifepristone was high but now with the lower dose being used and each tablet costing approximately Rs 320/- this method is found to be cost effective. Indeed, medical abortion can be done safely, effectively and acceptably in the outpatient family planning department of urban and rural hospital of India. ${ }^{11}$

The aim of study was to compare the success rate of abortions in both groups, to compare the inductionabortion interval in both groups and to study the side effects of the drugs.

\section{METHODS}

This study was conducted in department of obstetrics and gynecology, NIMS Medical College, Jaipur, India from June 2017-August 2017.

Total 100 cases were enrolled. they were divided in two groups:
- Group A- (50 cases) -gestational age upto 49 days

- Group B- (50 cases) -gestation age upto 63 days

Study was initiated after obtaining Ethics committee permission. Study duration was three month from 1-62017 to $31-8-2017$.

\section{Inclusion criteria}

- Patient who were compliant with the protocol, who were ready to undergo surgical abortion in case of failure or excess bleeding

- Gestation age upto 63 days

- Patients who have early access to emergency services.

\section{Exclusion criteria}

- $\mathrm{HB}<10 \mathrm{gm} \%$

- $\quad$ Suspected ectopic, adenexal mass

- Hypersensitivity to mifepristone or misoprostol

- Patient on anticoagulant or having coagulopathy

- Any systemic disorder -liver, renal or cardiovascular disease.

Thorough clinical examination was done, and proper history was also taken. Blood group and HB was done as routine investigation. Sonography was done only in cases suspected to be ectopic pregnancy.

Written consent was taken as per form $\mathrm{C}$.

Patients were given tablet mifepristone $200 \mathrm{mg}$. on first day then after $48 \mathrm{hrs}$. tablet misoprostol 400ugm. was given vaginally. If no bleeding occurs after $48 \mathrm{hrs}$, , then tablet misoprostol $400 \mathrm{mcg}$ was repeated.

Women were called after 14 days and Ultrasound was done for confirmation of abortion. Women were asked to report immediately if they develop any of the following problem-

- Excessive and prolonged bleeding

- Fainting or syncopal attack

- Fever>1010F

- Foul smelling purulent discharge

Side effects of drugs were also asked

- Nausea

- Vomiting, diarrhea

- Pain abdomen

- Fever.

\section{RESULTS}

The age group of women in present study varied from 18 to 40 years. The maximum number of women $(40 \%$ in Group A and 38\% in Group B belonged to 21-25 years of 
age. There were $34 \%$ in Group A and $36 \%$ in Group B belonging to 26-30 years of age. $\mathrm{P}$ value was 0.157 which was statistically not significant. In present study $\mathrm{p}$ value $<0.05$ was statistically significant.

Table 1: Distribution of cases according to age group $(\mathrm{n}=100)$.

\begin{tabular}{|lllll|}
\hline \multirow{2}{*}{ Age group (in years) } & \multicolumn{2}{c}{ Group-A } & \multicolumn{2}{c|}{ Group-B } \\
& No. & $\mathbf{\%}$ & No. & \% \\
\hline $18-20$ & 6 & 12 & 3 & 6 \\
\hline $21-25$ & 20 & 40 & 19 & 38 \\
\hline $26-30$ & 17 & 34 & 18 & 36 \\
\hline $31-35$ & 4 & 8 & 10 & 20 \\
\hline$>36$ & 3 & 6 & 0 & 0 \\
\hline Total & 50 & & 50 & \\
\hline
\end{tabular}

$\mathrm{P}$ value $=0.157$

Table 2: Distribution of cases according to duration of amenorrhea.

\begin{tabular}{|llll|}
\hline Group A & Group B \\
$\begin{array}{l}\text { No. of } \\
\text { patients }\end{array}$ & $\begin{array}{l}\text { Duration of } \\
\text { amenorrhea } \\
\text { (in days) }\end{array}$ & $\begin{array}{l}\text { No. of } \\
\text { patients }\end{array}$ & $\begin{array}{l}\text { Duration of } \\
\text { amenorrhea } \\
\text { (in days) }\end{array}$ \\
\hline 30 & $<40$ days & 18 & $50-55$ days \\
\hline 15 & $41-45$ days & 28 & $56-59$ days \\
\hline 5 & $46-49$ days & 4 & $60-63$ days \\
\hline
\end{tabular}

In present study in Group A 30 patients had amenorrhea of less than 40 days, 15 patients had amenorrhea between 41-45 days while only 5 patients had amenorrhea between 46-49 days.

In Group B 28 patients had amenorrhea between 56-59 days, 18 patients had amenorrhea 50-55 days, while only 4 patients had ameorrhea $60-63$ days.

Table 3: Distribution of cases according to days of bleeding.

\begin{tabular}{|lll|}
\hline Days of bleeding & $\begin{array}{l}\text { No. of patients } \\
\text { in Group A }\end{array}$ & $\begin{array}{l}\text { No. of patients } \\
\text { in Group B }\end{array}$ \\
\hline$<5$ days & 2 & 5 \\
\hline 5-10 days & 36 & 12 \\
\hline 11-13 days & 10 & 31 \\
\hline$>14$ days & 2 & 2 \\
\hline
\end{tabular}

In Group A 36 patients had bleeding per vagina for only 5-10 days, 10 patients had bleeding for 11-13 days,2 patients had bleeding for $<5$ days and 2 patients had bleeding for $>14$ days.

In Group B 31 patients had bleeding for 11-13 days, 12 patients had bleeding for 5-10 days, 5 patients had bleeding for $<5$ days while only 2 patients had bleeding for $>14$ days.
As period of amenorrhea is more in Group B patients so maximum patients had prolonged bleeding for 11-13 days while in Group A patient's period of amenorrhea is less so maximum patients had bleeding only for 5-10 days. This can be explained by the fact that bigger product of conception need more time for expulsion.

In present study 2 patient in Group $A$ and 2 patients in Group B had bleeding for more than 14 days although the amount of bleeding was minimal in both groups and sonography done on day 14 showed retained product of conception for which suction and evacuation was done under general anaesthsesia. Only 1 patient of group B had severe bleeding for which suction evacuation was done immediately and blood was transfused.

Table 4: Distribution of cases according to induction abortion interval.

\begin{tabular}{|lllll|}
\hline Induction abortion & \multicolumn{2}{c|}{ Group A } & \multicolumn{2}{c|}{ Group B } \\
\hline interval (in hours) & No. & \% & No. & $\%$ \\
\hline <4 hrs. & 40 & 80 & 35 & 70 \\
\hline >4hrs. & 10 & 20 & 15 & 30 \\
\hline Total & 50 & 100 & 50 & 100 \\
\hline
\end{tabular}

$\mathrm{P}$ value $=0.24$

In majority of women the induction abortion interval was <4hrs: $80 \%$ in Group A and $70 \%$ in Group B respectively. Induction abortion interval was $>4 \mathrm{hrs}$. in $20 \%$ of Group A and $30 \%$ of group B. The calculated P value was 0.24 which was statistically not significant. Time taken for abortion was more in Group B then Group A as can be explained by the fact that period of gestation was more in group B patients, so they took more time for abortion.

Table 5: Distribution of cases according to side effects.

\begin{tabular}{|lllll|}
\hline \multirow{2}{*}{ Side effects } & Group A & \multicolumn{2}{c|}{ Group B } \\
\hline Pain abdomen & No. & \% & No. & \% \\
\hline Nausea & 8 & 16 & 19 & 38 \\
\hline Diarrhoea & 5 & 10 & 15 & 30 \\
\hline Vomiting & 0 & 0 & 1 & 2 \\
\hline
\end{tabular}

Pain abdomen ( $p$ value $=0.02)$, Nausea ( $p$ value $=0.018)$, Diarrhoea $(\mathrm{p}$ value $=0.31)$, Vomiting $(\mathrm{p}$ value $=0.65)$

Major side effect reported by women in our study was pain abdomen $16 \%$ in Group A and $38 \%$ in Group B. Nausea was second major adverse effect of medical abortion, found in $10 \%$ and $30 \%$ in Group A and Group $\mathrm{B}$ respectively. $\mathrm{P}$ value was for pain abdomen was $(0.02)$ and $\mathrm{P}$ value for nausea was 0.018. The difference between both groups were statistically significant. In group B the gestation age is more so there is more pain abdomen for expulsion of products of conception.

Diarrhoea and vomiting was reported in $0 \%$ and $2 \%$ in Group A and 2\% and 6\% of Group B respectively. The difference was statistically not significant in both groups. 
Table 6: Distribution of case according to success rate in both groups.

\begin{tabular}{|lllll|}
\hline \multirow{2}{*}{ Outcome } & Group A & \multicolumn{3}{c}{ Group B } \\
& No. & \% & No. & \% \\
\hline Success & 48 & 96 & 47 & 94 \\
\hline Failure & 2 & 4 & 3 & 6 \\
\hline Total & 50 & & 50 & \\
\hline
\end{tabular}

The Mifepristone and Misoprostol combination regimen given for first trimester abortion was found to be highly successful in both groups. $96 \%$ patients in Group A aborted easily while $94 \%$ in group B patient aborted. In group A 2 patient had incomplete abortion for which evacuation was done while in group B failure was seen in 3 patients. One patient had heavy bleeding for which evacuation had been done and two patients had retained products of conception which was diagnosed in USG done after 14 days.

$\mathrm{P}$ value is more than 0.05 so the difference between both groups is statistically not significant.

\section{DISCUSSION}

The patients enrolled in present study belonged to $18-40$ years of age. Maximum patients $40 \%$ in Group A and $38 \%$ in Group B were of $21-25$ years of age.

The mean age was 26. 53 years in Group A and 26. 93 years in Group B in study conducted by Deshpande et al. ${ }^{12}$

In Ashok et al study the mean age of women was 26 years. $^{13}$

In present study maximum patients had amenorrhea <40 days in group A and maximum patients had amenorrhea 56-59 days in group B.

In group A maximum patients had bleeding for 5-10 days while in group B maximum patient had bleeding for 1113 days.

$80 \%$ of patients in group A aborted quickly within 4 hours of taking of tablet misoprostol while in group B $70 \%$ patients aborted within 4 hours of taking of tablet misoprostol.

In present study the side effects reported by the women were that majority of women had pain abdomen $16 \%$ in Group A and 38\% in Group B, but the pain resolved on it's own, no analgesic was required. Nausea was reported in $10 \%$ of Group A and $30 \%$ of Group B patients. P values were 0.02 for abdominal pain and 0.018 for nausea. The differences between both groups were statistically significant. As in Group B the gestation age is more so bigger size gestation sac when expelled causes more pain abdomen and nausea.
Diarrhea and vomiting were reported in $0 \%$ and $4 \%$ of Group A and 2\% and 6\% in Group B respectively. The differences between both groups were statistically not significant.

In the study conducted by Deshpande et al abdominal pain was seen in $15 \%$ and $37.50 \%$ in women of Group A and Group B respectively. ${ }^{12}$

In a study conducted by Kallner et al nausea was noted in $86.7 \%$ in group with $<50$ days of gestation age and 87 . $5 \%$ in the group with 50-63 days of gestation age. ${ }^{14}$ Vomiting was reported in $52.2 \%$ in group with $<50$ days of gestation and $62.5 \%$ in group with 50-63 days of gestation age.

The combination of mifepristone and misoprostol was found to be successful in inducing abortion in $96 \%$ of Group A and $94 \%$ in Group B patients. This shows that mifepristone and misoprostol combination can be used for medical termination upto 63 days of gestation.

\section{CONCLUSION}

From present study we conclude that medical abortion is safe, affordable, effective and easily acceptable method for first trimester termination.

Medical abortion of pregnancy has recently been approved by WHO and FOGSI upt 63 days (9 weeks). Previously it was approved only upto 49 days (7 weeks).

If proper counselling of patients is done, then medical abortion can be successfully performed thus we can avoid all the complications of surgical abortion.

However, we should explain the patient the risk of increased blood loss as the gestation age increase and also the chance of retained products of conception in advance gestation age.

\section{ACKNOWLEDGMENTS}

The authors are grateful to all residents and staff members of NIMS medical college, Department of obstetrics and gynecology for their help and support.

Funding: No funding sources

Conflict of interest: None declared

Ethical approval: The study was approved by the Institutional Ethics Committee

\section{REFERENCES}

1. Cunningham FG, Leveno KJ, Bloom SL, Haulh JC, Glistrap LC, Wenstrom KD, editors. Abortion. William textbook of obstetrics.

2. World Health Organization, Department of Reproductive Health and Research. Unsafe abortion: 
Global and regional estimates of the incidence of unsafe abortion and associated mortality in 2003. $5^{\text {th }}$ ed. Sexual and reproductive health. Available at http://apps.who.int/iris/bitstream/10665/43798/1/978 9241596121_eng.pdf

3. Megh M. FOGSI. comprehensive abortion care and post abortion contraception. FOGSI focus. 2012:15.

4. Creinin MD, Schwartz JL, Pymar HC, Fink W. Efficacy of mifepristone followed on same day by misoprostol for early termination of pregnancy: report of randomized trial. BJOG. 2001;108:469-73.

5. International consensus conference on nonsurgical(medical) abortion in early first trimester on issues related to regimens and service delivery. Frequently asked clinical questions about medical abortion. Geneva: World health organization 2006.

6. Kurtkoti K. FOGSI focus on medical abortion. 2010:5,27,31.

7. Ellertson C, Waldman SN. The MifepristoneMisoprostol regimen for early medical abortion. Curr Womens Health Rep. 2001;1:184-190.

8. Trupin S, Moreno C. Medical abortion: overview and management. Medscape Womens Health. 2001;6:4.

9. Kulier R, Gulmezoglu AM, Hofmeyer GJ, Chang LN, Campana A. Medical methods for first trimester abortion. Cochrane Database Syst Rev. 2004 Jan $1 ; 2(2)$.

10. Mittal S, editor. 2.2.2. 2003. Consortium on National consensus for Medical abortion in India. 2003:122-3.
Available

http://www.aiims.edu/aiims/events/gynaeworkshop/29-30\%20JUNE-2008/Poster.pdf

11. Coyaji K, Elul B, Krishna U. MifepristoneMisoprostol abortion: a trial in rural and urban Maharashtra, India. Contraception. 2002;66:33-40.

12. Deshpande S, Yelikar K, Deshmukh A, Kapil K. Comparative study of medical abortion by mifepristone with vaginal misoprostol in women $<49$ days versus 50-63 days of amenorhoea. J Obstet Gynecol. 2010;60(5):403-7.

13. Ashok PW, Penney GC, Flett GM, Templeton A. An effective regimen for early medical abortion: a report of 2000 consecutive case. Hum Reprod. 1998;13(10):2962-5.

14. Kopp Kallner H, Fiala C, Stephansson O, GemzellDanielsson K. Homeself administration of vaginal misoprostol for medical abortion at 50-63 days compared with gestation of below 50 days. Hum Reprod. 2010;25(5):1153-7.

Cite this article as: Bhojwani $\mathrm{P}$, Meena $\mathrm{P}$, Verma GS. Efficacy of combination of tablet mifepristone and misoprostol for first trimester pregnancy termination at different gestational age. Int $\mathbf{J}$ Reprod Contracept Obstet Gynecol 2018;7:248-52. 